\title{
A pandemia de COVID-19 no Brasil: crônica de uma crise sanitária anunciada
}

Guilherme Loureiro Werneck 1,2

Marilia Sá Carvalho 3

doi: 10.1590/0102-311X00068820

A pandemia da COVID-19 pelo novo coronavírus (SARS-CoV-2) tem se apresentado como um dos maiores desafios sanitários em escala global deste século. Na metade do mês de abril, poucos meses depois do início da epidemia na China em fins de 2019, já haviam ocorrido mais de 2 milhões de casos e 120 mil mortes no mundo por COVID-19, e estão previstos ainda muitos casos e óbitos nos próximos meses. No Brasil, até então, tinham sido registrados cerca de 21 mil casos confirmados e 1.200 mortes pela COVID-19.

$\mathrm{O}$ insuficiente conhecimento científico sobre o novo coronavírus, sua alta velocidade de disseminação e capacidade de provocar mortes em populações vulneráveis, geram incertezas sobre quais seriam as melhores estratégias a serem utilizadas para o enfrentamento da epidemia em diferentes partes do mundo. No Brasil, os desafios são ainda maiores, pois pouco se sabe sobre as características de transmissão da COVID-19 num contexto de grande desigualdade social, com populações vivendo em condições precárias de habitação e saneamento, sem acesso sistemático à água e em situação de aglomeração.

De forma bastante esquemática e simplista, a resposta à pandemia da COVID-19 poderia ser subdivida em quatro fases: contenção, mitigação, supressão e recuperação. A primeira fase, de contenção, inicia antes do registro de casos em um país ou região. Envolve, principalmente, o rastreamento ativo dos passageiros vindos do exterior e seus contatantes, visando a evitar ou postergar a transmissão comunitária. $\mathrm{Na}$ atual pandemia considera-se que uma fase de contenção exemplar foi essencial para que o impacto inicial da pandemia fosse menor em Taiwan, Singapura e Hong Kong, mesmo estando próximos da China. A experiência prévia com a primeira grande epidemia de síndrome respiratória aguda grave (SRAG) causada por coronavírus deste século (2003) pode, pelo menos parcialmente, explicar a bem sucedida fase de contenção nesses locais.

A segunda fase, de mitigação, inicia quando a transmissão sustentada da infecção já está instalada no país. O objetivo aqui é diminuir os níveis de transmissão da doença para os grupos com maior risco de apresentarem quadros clínicos graves, além, claro, do isolamento dos casos positivos identificados. Essas medidas, denominadas de "isolamento vertical", são em geral acompanhadas de algum grau de redução do contato social. Em geral começa com o cancelamento de grandes eventos, seguido paulatinamente por ações como a suspen-
1 Instituto de Medicina Social, Universidade do Estado do Rio de Janeiro, Rio de Janeiro, Brasil.

2 Instituto de Estudos em Saúde Coletiva, Universidade Federal do Rio de Janeiro, Rio de Janeiro, Brasil.

3 Programa de Computação Científica, Fundação Oswaldo Cruz, Rio de Janeiro, Brasil. 
são das atividades escolares, proibição de eventos menores, fechamento de teatros, cinemas e shoppings, recomendações para a redução da circulação de pessoas. É o que se convencionou chamar de "achatar a curva" da epidemia.

Uma fase de supressão pode ser necessária quando as medidas anteriores não conseguem ser efetivas, seja porque sua implementação não pode ser concretizada de forma adequada e imediata (p.ex.: insuficiência de testes diagnósticos necessários para identificar indivíduos infectantes logo no início da epidemia) ou porque a redução alcançada na transmissão é insuficiente para impedir o colapso na atenção à saúde. Na fase de supressão são implantadas medidas mais radicais de distanciamento social, de toda a população. Aqui o objetivo é adiar ao máximo a explosão do número de casos, por tempo suficiente até que a situação se estabilize no campo da assistência à saúde, procedimentos de testagem possam ser ampliados e, eventualmente, alguma nova ferramenta terapêutica ou preventiva eficaz (p.ex.: vacina) esteja disponível. Há controvérsias 1 em relação a essas medidas de "isolamento horizontal", particularmente no que concerne às suas repercussões econômicas, sociais e psicológicas em âmbito populacional 2.

Por fim, e não menos importante, é a fase de recuperação, quando há sinal consistente de involução da epidemia e o número de casos se torna residual. Essa última fase requer uma organização da sociedade para a reestruturação social e econômica do país. E, certamente, intervenção do Estado.

No Brasil, a questão de qual seria a estratégia mais adequada para o contexto atual da epidemia, se o "isolamento vertical" ou o "isolamento horizontal", tem dominado o debate em diferentes setores da sociedade civil, mas também entre pesquisadores e profissionais direta ou indiretamente envolvidos com o enfrentamento da epidemia. Esse debate tem analogia com o dilema da escolha de intervenções baseadas em "estratégias de alto risco" ou "estratégias populacionais" 3 .

O seminal trabalho de Geoffrey Rose influencia até hoje o debate sobre intervenções em saúde pública. Em resumo, intervenções baseadas em "estratégias de alto risco" seriam aquelas orientadas para a redução do impacto da doença e suas complicações em um subconjunto populacional considerado de mais alto risco. Já a "estratégia populacional" propõe uma abordagem preventiva para toda a população. No âmbito das doenças crônicas, com alta prevalência, há uma preferência por estratégias populacionais, pois os benefícios das ações preventivas seriam sentidos não só pela população de mais alto risco, mas por todos. Assumindo que os riscos à saúde se distribuem continuamente numa população, uma abordagem populacional abrangeria um maior contingente de pessoas responsáveis pela maior carga da doença em âmbito populacional 4 . Já em relação às doenças transmissíveis, o enfoque de alto risco tem sido mais frequentemente advogado, pois a abordagem focalizada na população de maior risco (de transmitir e/ou de adquirir a infecção) seria mais eficiente para limitar o processo de transmissão para toda a população ${ }^{5}$. E, algumas vezes, adota-se uma combinação de ambas. É o caso da aids, com estratégias populacionais, por exemplo, o incentivo ao uso do condom, associadas a campanhas voltadas para as populações de maior risco, como os trabalhadores do sexo 6 .

A adoção de diferentes estratégias de isolamento social, vertical ou horizontal, deve ser pautada em uma análise da situação e progressão da epidemia em um determinado contexto. Dessa forma, sob o ponto de vista estritamente teórico, uma estratégia efetiva de "isolamento vertical" poderia ser a mais eficiente também por reduzir as repercussões econômicas e sociais associadas ao "isolamento horizontal". Ocorre, porém, que as condições para a 
execução de um "isolamento vertical" efetivo, na situação atual da epidemia no Brasil, são muito limitadas. Isso se dá, em parte, pela alta velocidade de expansão da infecção e as dificuldades para o monitoramento e vigilância estrita de casos e contatos, uma vez que a proporção de assintomáticos se aproxima de $80 \%$ dos infectados. Além disso e, principalmente, pela ausência de um sistema de testagem amplo estabelecido logo no início da epidemia de forma a permitir a identificação precoce dos infectados. De fato, a experiência da China mostra que, no início da epidemia, cerca de $86 \%$ das infecções não foram detectadas, mas constituíram a fonte de infecção para cerca de $79 \%$ dos casos 7 . Não à toa, os progressos no controle da epidemia na China só ocorreram após a implantação de medidas amplas e drásticas de distanciamento social. Nos países que apresentam amplas restrições tanto na capacidade de testagem nos momentos inicias da epidemia como na cobertura da assistência ao paciente grave, como os Estados Unidos e a Itália, o "isolamento vertical" foi inicialmente executado, porém, a evolução rápida do número de casos exigiu, ainda que tardiamente, a introdução da estratégia de supressão via “isolamento horizontal”. Da mesma forma, no Reino Unido, a estratégia de isolamento vertical foi inicialmente preconizada, mas a evolução da epidemia e as projeções disponíveis levaram a uma mudança de rumo, com a adoção da estratégia de supressão baseada em isolamento social horizontal.

Há tempos que a comunidade científica do campo das doenças infecciosas alerta que o advento de novas pandemias não é uma questão de "se", mas de "quando" irá ocorrer 8 . O século XXI presenciou várias epidemias que puderam ser contidas em algum nível temporal ou geográfico, como as duas epidemias de coronavírus (pelo SARS-CoV e a síndrome respiratória do Oriente Médio - MERS), as epidemias de Ebola na África e a epidemia de gripe aviária (H5N1). Em conjunto elas provocaram menos mortes do que a COVID-19. A pandemia de influenza H1N1 de 2009, para a qual uma vacina estava disponível, foi devastadora, estimando-se que entre $150 \mathrm{mil} \mathrm{a} 575$ mil pessoas morreram de causas associada à infecção 9 . O número de mortes que serão provocadas por COVID-19 é uma incógnita, mas estimativas atuais indicam que poderá superar 2 milhões de óbitos, mesmo com a implantação de medidas de supressão precoces 10.

No Brasil, o panorama é incerto e as estimativas válidas e confiáveis do número de casos e óbitos por COVID-19 esbarram na ausência de dados confiáveis, seja dos casos ou da implantação efetiva das medidas de supressão, frente às recomendações contraditórias das autoridades em cada nível de governo. Entre as regiões do país, trabalhos preliminares baseados em dados de mobilidade interurbana apontam os caminhos potenciais da difusão da epidemia como instrumento de alocação dos recursos necessários à adequada assistência, já escassos 11. Pouco se sabe sobre como a epidemia se propagará e afetará as comunidades de baixa renda, um panorama completamente novo, considerando os países mais afetados até agora.

A epidemia de COVID-19 encontra a população brasileira em situação de extrema vulnerabilidade, com altas taxas de desemprego e cortes profundos nas políticas sociais. Ao longo dos últimos anos, especialmente após a aprovação da Emenda Constitucional no 95, que impõe radical teto de gastos públicos e com as políticas econômicas implantadas pelo atual governo, há um crescente e intenso estrangulamento dos investimentos em saúde e pesquisa no Brasil. É justamente nesses momentos de crise que a sociedade percebe a importância para um país de um sistema de ciência e tecnologia forte e de um sistema único de saúde que garanta o direito universal à saúde. 
No momento, as decisões imediatas devem buscar poupar vidas, garantindo a assistência de boa qualidade ao paciente grave. É também indispensável minimizar os danos econômicos, sociais e psicológicos das populações mais vulneráveis, por meio da adoção de medidas fiscais e sociais 12. Devemos levantar nossas vozes em defesa do sistema único de saúde e exigir que os que hoje governam o país se engajem na defesa da vida do nosso povo, do contrário, serão responsabilizados pela promoção daquilo que se apresenta potencialmente como uma das maiores tragédias sanitárias já vividas neste país.

\section{Colaboradores}

Ambos os autores contribuíram com a concepção, redação e revisão do manuscrito, e aprovaram a versão final.

\section{Informações adicionais}

ORCID: Guilherme Loureiro Werneck (0000-00031169-1436); Marilia Sá Carvalho (0000-0002-95660284).

1. Ioannidis JPA. Coronavirus disease 2019: the harms of exaggerated information and nonevidence-based measures. Eur J Clin Invest 2020; 50:e13222.

2. Kissler SM, Tedijanto C, Lipsitch M, Grad Y. Social distancing strategies for curbing the COVID-19 epidemic. medRxiv 2020; 24 mar. https://www.medrxiv.org/content/10.1101/2 020.03.22.20041079v1.

3. Rose G. The strategy of preventive medicine. Oxford/New York: Oxford University Press; 1992.

4. Chor D, Faerstein E. Um enfoque epidemiológico da promoção da saúde: as idéias de Geoffrey Rose. Cad Saúde Pública 2000; 16:241-4.

5. Koopman JS, Simon CP, Riolo CP. When to control endemic infections by focusing on highrisk groups. Epidemiology 2005; 16:621-7.

6. Chang LW, Serwadda D, Quinn TC, Wawer MJ, Gray RH, Reynolds SJ. Combination implementation for HIV prevention: moving from clinical trial evidence to population-level effects. Lancet Infect Dis 2013; 13:65-76.

7. Li R, Pei S, Chen B, Song Y, Zhang T, Yang W, et al. Substantial undocumented infection facilitates the rapid dissemination of novel coronavirus (SARS-CoV2). Science 2020; [Epub ahead of print].

8. Wolfe N. The viral storm: the dawn of a new pandemic age. Ne York: Times Books; 2011.

9. Dawood FS, Iuliano AD, Reed C, Meltzer MI, Shay DK, Cheng P-Y, et al. Estimated global mortality associated with the first 12 months of 2009 pandemic influenza A H1N1 virus circulation: a modelling study. Lancet Infect Dis 2012; 12:687-95.

10. Walker P, Whittaker C, Watson O, Baguelin M, Ainslie K, Bhatia S, et al. Report 12: The global impact of COVID-19 and strategies for mitigation and suppression. http://spiral.imperial. ac.uk/handle/10044/1/77735 (acessado em 03/Abr/2020).

11. Coelho FC, Lana RM, Cruz OG, Codeco CT, Villela D, Bastos LS, et al. Assessing the potential impact of COVID-19 in Brazil: mobility, morbidity and the burden on the health care system. medRxiv 2020; 26 mar. https://www. medrxiv.org/content/10.1101/2020.03.19.200 39131v2.

12. Apuzzo M, Pronczuk M. COVID-19's economic pain is universal. But relief? Depends on where you live. The New York Times 2020; 23 mar. https://www.nytimes.com/2020/03/23/ world/europe/coronavirus-economic-reliefwages.html. 